\title{
Impact of climate and sea level change on coastal
} evolution

\section{Accra, Ghana, 8-12 October 2012}

Kwasi Appeaning-Addo, S.W. Laryea, B.A. Foli and C.L. Allotey

Department of Marine and Fisheries Sciences, University of Ghana; kappeaning-addo@ug.edu.gh

$T^{\text {ne }}$ he third West African Quaternary Research Association (WAQUA) workshop, hosted by the Department of Marine and Fisheries Sciences, University of Ghana, was held at the Institute for Local Government Studies in Accra. The objective of the workshop was to identify how humans adapted to past climatic and sea level changes, and to discuss future adaptation strategies through a multidisciplinary approach.

Twenty-seven scientists from five countries attended the workshop. The inaugural lecture was given by Dr. Thomas Kwasi Adu of the Geological Survey Department of Ghana. He spoke about the causes of sea-level rise and coastal change, and their implications for coastal regions. His lecture stressed the fact that important planning decisions for sea-level rise should be based on the best available scientific knowledge and careful consideration of long-term benefits for a sustainable future. He recommended that decisions on adaptation or mitigation measures should also take into consideration economic, social, and environmental costs.

Sixteen scientific papers were presented and discussed on various topics covering sea level rise, coastal erosion and climate change issues. In particular, the presentations addressed the impact of sealevel changes on coastal tourism development; the linkages between sea-level rise and ground water quality, hydrodynamics, upwelling and biogeochemistry in the Gulf of Guinea; paleoclimatic evidences from the quaternary coastal deposits from Nigeria; dynamics of ocean surges and their impacts on the Nigerian coastline; and the effect of climatic extreme events on reservoir water storage in the Volta Basin in Ghana.

The workshop provided a platform for scientists to share knowledge and information on their respective areas of research. At the end of the presentation sessions, the plenum agreed that research on sea-level rise should be particularly encouraged and that further activities to bring together scientists working in this area should be organized. To stimulate interest and expose students to new methods, regular international workshops or summer schools will be held to bring together students and experts from within and outside the subregion.
The meeting participants then went on a guided tour of coastal communities along the eastern coast of Ghana. One of them was Keta, a coastal town in the Volta Region that was partly destroyed by sea erosion at the end of the $20^{\text {th }}$ century. Keta is situated on a sandspit separating the Gulf of Guinea from the Keta Lagoon. Due to this double waterfront, the city area is particularly vulnerable to erosion. It is flooded from the ocean front during high tides and from the lagoon front during heavy runoff, especially in the rainy seasons. During devastating erosion events between 1960 and 1980, more than half of the town area has been washed away. The photo (Fig. 1) shows Keta in 1985. Since 1999 more than 80 million US\$ have been invested to protect, restore and stabilize the coast of Keta.

The next WAQUA workshop will be held in Senegal in 2014.

\section{Acknowledgements}

We express our sincere gratitude to INQUA, PAGES, PAST and the University of Ghana for sponsoring this workshop. We are also grateful to the local hosts, the Department of Marine and Fisheries Sciences, University of Ghana and the Ghanaian Institute of Local Government Studies.

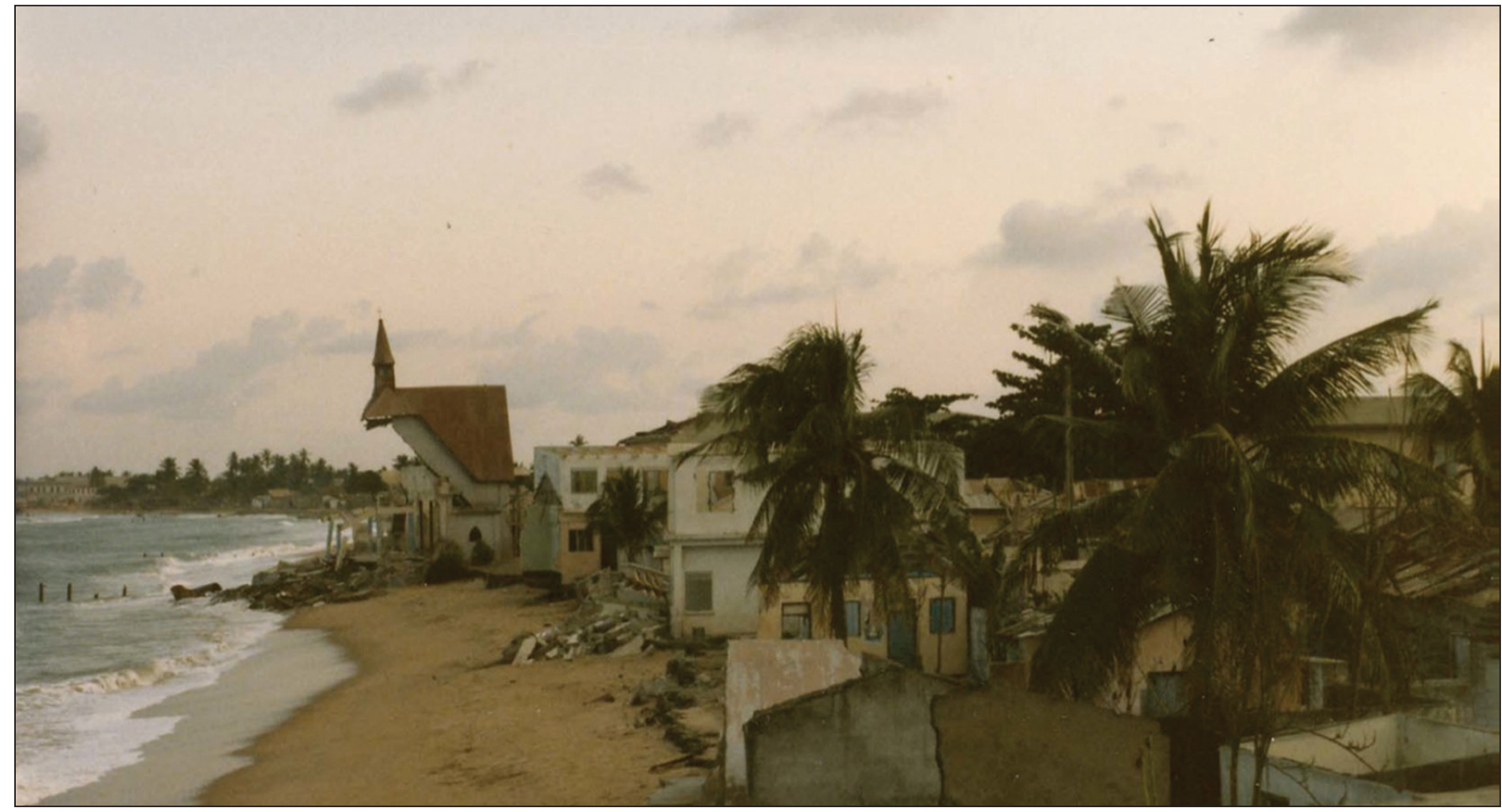

Figure 1: This photo from 1985 shows a section of the Keta town destroyed by sea erosion. Photo by Beth Knittle. 